\title{
A Direct Power Control of the Doubly Fed Induction Generator Based on the Three-Level NSVPWM Technique
}

\author{
Habib Benbouhenni*, Zinelaabidine Boudjema**, Abdelkader Belaidi* \\ * Laboratoire d'Automatique et d'Analyse des Systèmes (LAAS), Departement de Génie Electrique, Ecole Nationale \\ Polytechnique d'Oran Maurice Audin, Oran, Algeria. \\ (habib0264@gmail.com, balaidiaek@gmail.com) \\ **Electrical Engineering Department, Hassiba Benbouali University, Chlef, Algeria. \\ (boudjemaa1983@yahoo.fr)

\begin{abstract}
*Corresponding Author; Habib Benbouhenni, BP: 50B Ouled Fares Chlef Algeria, Tel: +213663956329, habib0264@gmail.com
\end{abstract} \\ Received: $x x . x x . x x x x$ Accepted:xx.xx.xxxx
}

\begin{abstract}
The paper proposes a direct power control (DPC) scheme for the doubly fed induction generator (DFIG) for variable speed wind-power generation. The machine is connected as a generator. Its rotor is fed by a three-level NPC inverter. We propose to control the DFIG with a technique based on the DPC control performances. A combination of a three-level neural space vector pulse width modulation (3L-NSVPWM) strategy and reactive and active power controllers is made to replace hysteresis comparators used in the traditional DPC drive resulting in a fixed switching frequency of the power converter. The performances obtained by using this control technique are shown under Matlab/Simulink software.
\end{abstract}

Keywords: DFIG; DPC; three-level NPC inverter; 3L-NSVPWM.

$\begin{array}{ll}\text { Nomenclature } & \\ \text { DPC } & \text { Direct power control } \\ \text { DFIG } & \text { Doubly fed induction generator } \\ \text { SVPWM } & \text { Space vector pulse width modulation } \\ \text { NPC } & \text { Neutral point clamped } \\ \text { ANN } & \text { Artificial neural networks } \\ \text { FLC } & \text { Fuzzy logic controller } \\ \text { GSC } & \text { Grid side converter } \\ \text { SOSMC } & \text { Second order sliding mode controller } \\ \text { FOC } & \text { Field oriented control } \\ \text { PI } & \text { Proportional-integral } \\ \text { r, s } & \text { Rotor, stator. } \\ d, q & \text { Synchronous d-q axis. } \\ \text { SVM } & \text { Space vector modulation } \\ L_{r}, L_{s} & \text { Stator and rotor self-inductances. } \\ L_{m} & \text { Mutual inductance. } \\ R_{r}, R_{s} & \text { Stator and rotor resistances. } \\ \psi_{r}, \psi_{s} & \text { Rotor and Stator flux vectors. } \\ I_{s}, I_{r} & \text { Rotor and stator current vectors. } \\ V_{s}, V_{r} & \text { Rotor and stator voltage vectors. } \\ \mathrm{P}_{s}, \mathrm{Q}_{s} & \text { Active and reactive powers. }\end{array}$

\section{Introduction}

The DFIG control comprises both the rotor side converter (RSC) and grid side converter (GSC) controllers so that the RSC controls stator active and reactive powers and the GSC regulators DC link voltages as well as generating and independent reactive power that is injected into the grid [1]. The DFIG can be controlled by well-known field-oriented control [2], direct torque control [3] or direct power control [4]. However, the DPC control is similar to the DTC control. The DPC control scheme's goal is to control the reactive and active powers of the DFIG. In the traditional DPC control scheme, a two-level hysteresis comparator is used for the reactive power and a three-level hysteresis comparator for the active power [5]. On the other hand, the DPC control has many advantages, the simplest scheme, reliability, the fast dynamic response, and lower parameter dependency, but it has some drawbacks, such as the reactive and active powers ripples [6].

In [7], a modified DPC control was proposed based on second-order sliding mode controller (SOSMC) to regulate 
the active and reactive powers of the DFIG. In [8], the authors propose a three-level DPC strategy to control the DFIG-based wind turbine. In [9], the DPC strategy was proposed based on artificial neural networks (ANN) to control DFIG-based wind turbines. Sliding mode direct power control is proposed[10]. In [11], a modified DPC strategy was proposed based on space vector modulation (SVM) and proportional-integral (PI) controller to reduced harmonic distortion of current and power ripples. Model predictive direct power control [12].

In this work, a DPC control scheme is proposed based on the neural SVPWM strategy (NSVPWM) to control the DFIGbased wind turbine. This proposed strategy reduces the reactive power ripple, electromagnetic torque ripple, active power ripple and harmonic distortion of voltage compared to the traditional DPC control scheme. Section II is dedicated to the basic principles of the traditional DPC strategy has been shortly introduced. Section III presents the SVPWM based on the ANN controller for three-level NPC inverter. Section IV presents the proposed DPC strategy with a three-level NSVPWM technique. Section V presents the simulation results of both techniques. Finally conclusion has given in section VI.

\section{DPC control}

The traditional DPC control scheme of three-phase DFIGbased wind turbine is shown in Fig. 1. In this control system, the stator reactive and stator active powers are controlled by two hysteresis comparators and a switching table. This strategy is easy to implement and simple structure compared to field-oriented control.

The magnitude of stator flux, which can be estimated by:
Fig. 1 DPC control scheme.

$$
\left\{\begin{aligned}
\Psi_{s \alpha}= & \int^{t}\left(V_{s \alpha}-R_{s} I_{s \alpha}\right) d t \\
& 0 \\
\Psi_{s \beta}= & \int_{0}^{t}\left(V_{s \beta}-R_{s} I_{s \beta}\right) d t
\end{aligned}\right.
$$

Where $: V_{s \alpha}$ is the stator voltage linkage of $\alpha$-axis.

$\mathrm{V}_{\mathrm{s} \beta}$ : is the stator voltage linkage of $\beta$-axis.

The stator flux amplitude is given by:

$$
\Phi_{s}=\sqrt{\Psi_{s \alpha}^{2}+\Psi_{s \beta}^{2}}
$$

The stator flux angle is calculated by :

$$
\theta_{S}=\operatorname{arctg}\left(\frac{\Psi_{s \beta}}{\Psi_{s \alpha}}\right)
$$

Active and stator reactive powers is estimated using (4) and (5) [13].

$$
\begin{aligned}
& P_{s}=-\frac{3}{2} \frac{L_{m}}{\sigma \cdot L_{s} \cdot L_{r}} \cdot\left(V_{s .} \psi_{r \beta}\right) \\
& Q_{s}=-\frac{3}{2}\left(\frac{V_{s}}{\sigma \cdot L_{s}} \cdot \psi_{r \beta}-\frac{V_{s . L_{m}}}{\sigma \cdot L_{s} \cdot L_{r}} \cdot \psi_{r \alpha}\right)
\end{aligned}
$$

Where: $\mathrm{Lm}$ is the mutual inductance.

$\Psi_{\mathrm{r} \beta}$ : is the rotor flux linkage of $\beta$-axis.

$\Psi_{\mathrm{r} \alpha}$ : is the rotor flux linkage of $\alpha$-axis.

$$
\Psi_{s \alpha}=\sigma L_{r} I_{r \alpha}+\frac{M}{L_{s}} \Psi_{s}
$$

Where : $\Psi_{\mathrm{s} \alpha}$ : is the stator flux linkage of $\alpha$-axis.

$\Psi_{\text {s }}$ is the stator flux.

$\mathrm{I}_{\mathrm{r} \alpha}$ : is the rotor current linkage of $\alpha$-axis.

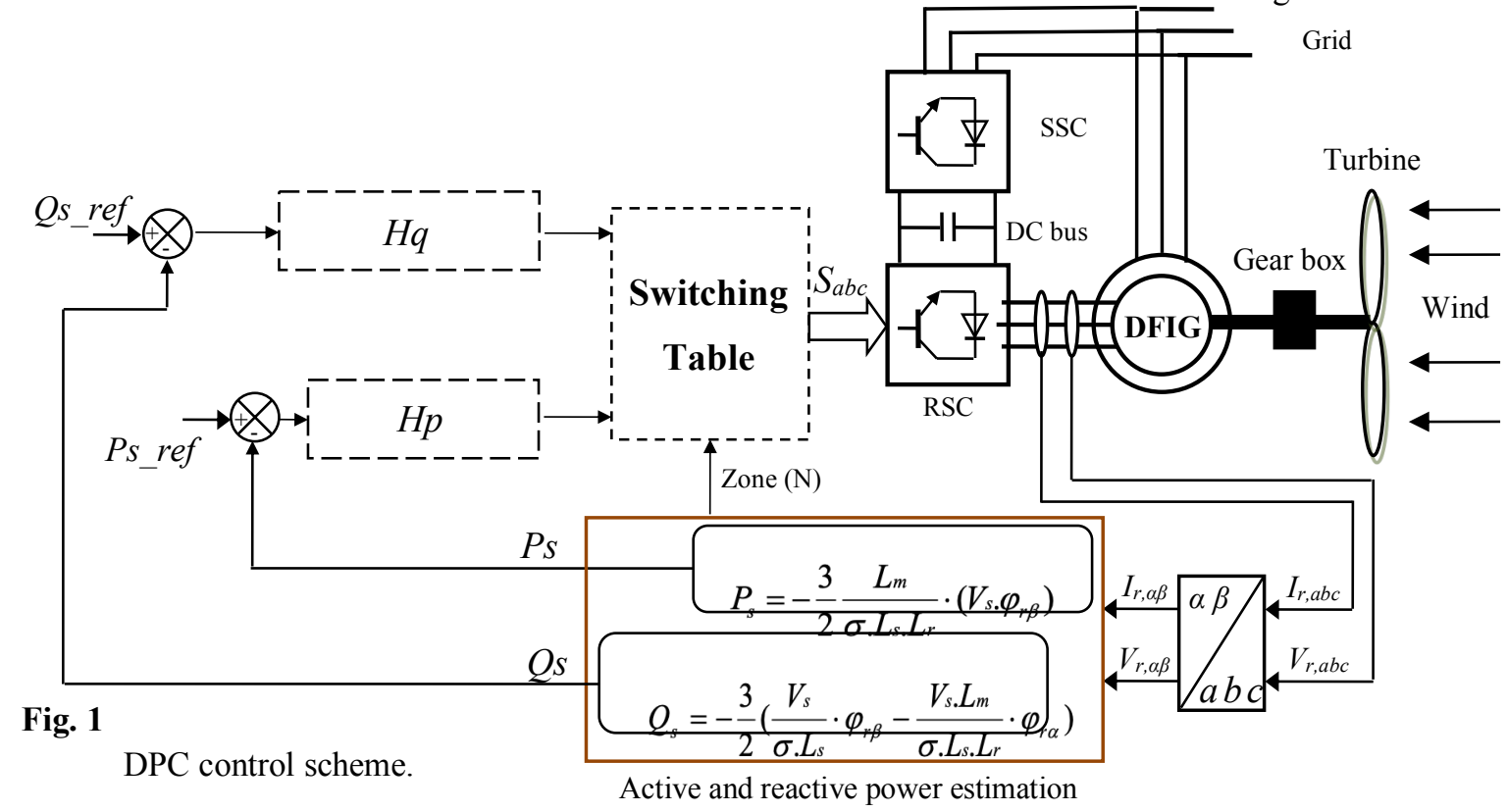


Fig. 2 Reactive power hysteresis comparator.

$\Psi_{s \beta}=\sigma L_{r} I_{r \beta}$

Where : $\Psi_{\mathrm{s} \beta}$ : is the stator flux linkage of $\beta$-axis.

$I_{r \beta}:$ is the rotor current linkage of $\beta$-axis.

$$
\left|\overline{\Psi_{s}}\right|=\frac{\left|\overline{V_{s}}\right|}{w_{s}}
$$

Where : $\mathrm{V}_{\mathrm{s}}$ is the stator voltage.

$$
\sigma=1-\frac{M^{2}}{L_{r} L_{s}}
$$

The reactive and active powers can be reformulated by inducing angle $\lambda$ between the rotor and stator vectors as follows :

$$
\begin{aligned}
& P_{s}=-\frac{3}{2} \frac{L_{m}}{\sigma \cdot L_{s} \cdot L_{r}} w_{s}\left|\psi_{s}\right|\left|\psi_{r}\right| \sin (\lambda) \\
& Q_{s}=-\frac{3}{2} \frac{w_{s}}{\sigma \cdot L_{s}}\left|\psi_{s}\right|\left(\frac{M}{L_{r}}\left|\psi_{r}\right| \cos (\lambda)-\left|\psi_{s}\right|\right)
\end{aligned}
$$

The derivation of the active and reactive powers can given by:

$$
\frac{d P_{s}}{d t}=-\frac{3}{2} \frac{L_{m}}{\sigma \cdot L_{s . L r}} w_{s}\left|\psi_{s}\right| \frac{d\left(\left|\psi_{r}\right| \sin (\lambda)\right)}{d t}
$$

$\frac{d Q_{s}}{d t}=-\frac{3}{2} \frac{M \cdot w_{s}}{\sigma \cdot L_{r} L_{s}}\left|\psi_{s}\right|\left(\frac{d\left(\left|\psi_{r}\right| \cos (\lambda)\right)}{d t}\right)$

In traditional DPC control scheme a two-level hysteresis comparator (Fig. 2) is used for the reactive power (Hq) and a three-level hysteresis comparator (Fig. 3) for the stator active power (Hp). Finally, based on the values of constants Hp and $\mathrm{Hq}$ and the position of the stator flux (6 region control), the inverter switching algorithm is as shown in Table 1 [14].

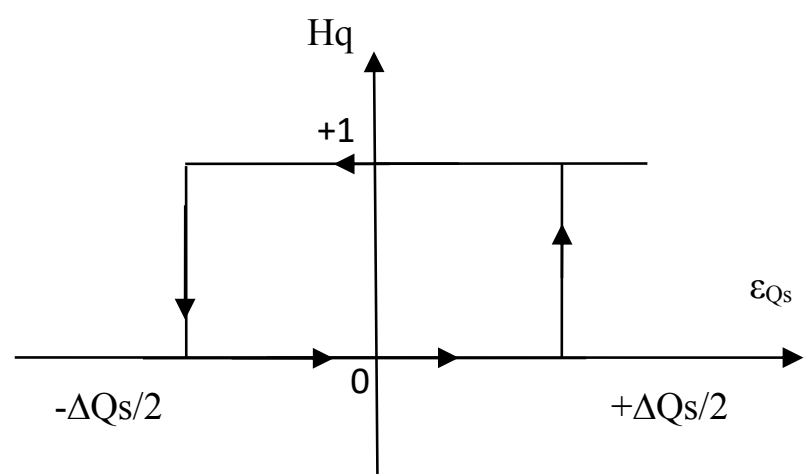

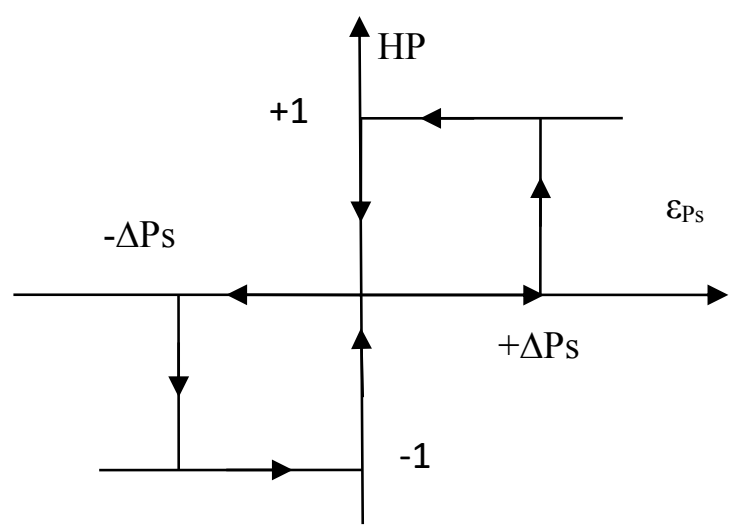

Fig. 3 Active power hysteresis comparator.

Table 1. Switching table for traditional DPC

\begin{tabular}{|c|c|c|c|c|c|c|c|}
\hline \multicolumn{2}{|c|}{$\mathbf{N}$} & $\mathbf{1}$ & $\mathbf{2}$ & $\mathbf{3}$ & $\mathbf{4}$ & $\mathbf{5}$ & $\mathbf{6}$ \\
\hline \multirow{3}{*}{ Hq } & $\mathbf{H p}$ & & & & & & \\
\hline \multirow{3}{*}{$\mathbf{1}$} & $\mathbf{1}$ & 5 & 6 & 1 & 2 & 3 & 4 \\
\cline { 2 - 8 } & $\mathbf{0}$ & 7 & 0 & 7 & 0 & 7 & 0 \\
\cline { 2 - 8 } & $\mathbf{- 1}$ & 3 & 4 & 5 & 6 & 1 & 2 \\
\hline \multirow{3}{*}{$\mathbf{0}$} & $\mathbf{1}$ & 6 & 1 & 2 & 3 & 4 & 5 \\
\cline { 2 - 7 } & $\mathbf{0}$ & 0 & 7 & 0 & 7 & 0 & 7 \\
\cline { 2 - 7 } & $\mathbf{- 1}$ & 2 & 3 & 4 & 5 & 6 & 1 \\
\hline
\end{tabular}

\section{Neural space vector pulse width modulation}

Traditionally the PWM strategy is widely used in variable speed drive of the AC machine, especially for vector control where the stator voltage and frequency can be controlled with minimum online computational requirement [15]. On the other hand, this strategy has the following drawbacks. This strategy gives more harmonic distortion. This strategy is unable to fully utilize the available DC bus supply voltage to the inverter. But, this strategy is easy to implement. In [16], PWM and neural networks are combined to reduce the harmonic distortion of current. Fuzzy PWM technique is proposed to regulate the reactive and active powers of DFIGbased wind turbine [17]. In [18], the author has proposed a new structure for SVPWM, this proposed strategy is simple and easy to implement. This proposed based on calculating the maximum (Max) and minimum (Min) of three-phase voltages. In [19], an SVPWM strategy of the three-level inverter has proposed, which based on the two-level SVPWM strategy. We remake that the SVPWM for threelevel NPC inverter reduces the harmonic distortion of voltage compared to SVPWM of a traditional inverter. The SVPWM strategy block represents the three-level inverter model as shown in Fig. 4. On the other hand, the block diagram of the hysteresis comparators is shown in Fig. 5. This strategy gives more harmonic distortion of stator voltage, active and reactive powers ripples of DFIG-based wind turbine. 
To improve the three-level SVPWM performances, additional use of the ANN controller is proposed in this work. The principle of the three-level NSVPWM strategy is similar to three-level SVPWM strategy. The difference is the use of ANN controllers to replace the hysteresis comparators. As shown in Fig. 6. In addition, the three-level NSVPWM strategy reduces the ripples in stator current, active and reactive powers ripples. On the other hand, this proposed strategy is easy to implement and simple scheme [20].

Table 2. Parameters of the LM algorithm

\begin{tabular}{|l|c|}
\hline Parameters of the LM & Values \\
\hline Number of hidden layer & 8 \\
\hline TrainParam.Lr & 0.02 \\
\hline TrainParam.show & 50 \\
\hline TrainParam.eposh & 300 \\
\hline TrainParam.goal & 0 \\
\hline TrainParam.mu & 0.9 \\
\hline Functions of activation & $\begin{array}{c}\text { Tensing, Purling, } \\
\text { gensim }\end{array}$ \\
\hline $\begin{array}{l}\text { Coeff of acceleration of convergence } \\
\text { (mc) }\end{array}$ & 0.9 \\
\hline
\end{tabular}

\section{DPC control with NSVPWM strategy}

The DPC control of three-phase DFIG with the application of three-level NSVPWM technique is shown in Fig. 9. The DPC with three-level NSVPWM technique (DPC-3LNSVPWM) is a modification of the classical DPC control scheme, where the switching table and two hysteresis

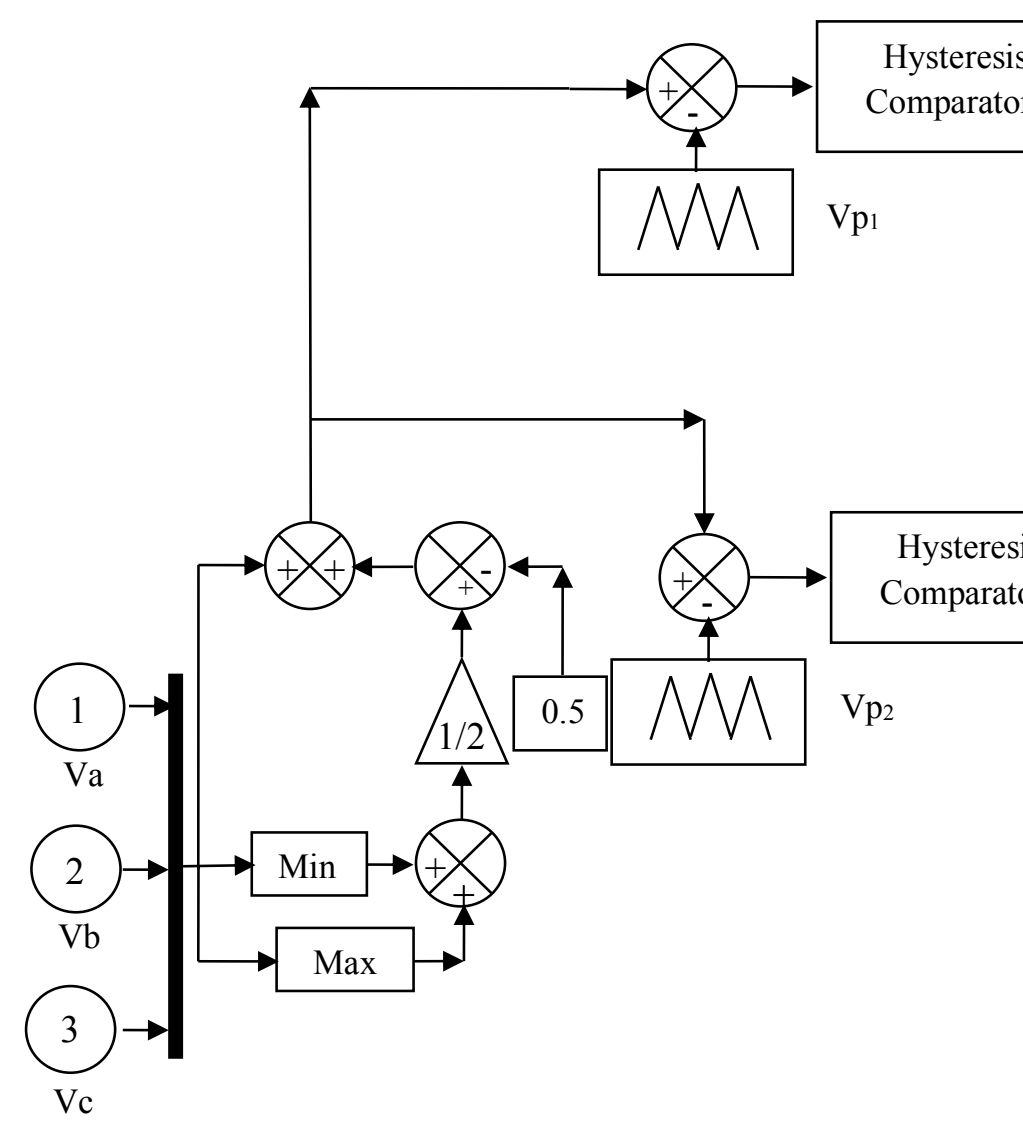

Fig. 4 Block diagram of three-level SVPWM technique. comparators, has been replaced by a 3L-NSVPWM technique and two PI controllers respectfully. This proposed strategy minimized the powers ripples and harmonic distortion compared to traditional DPC control scheme.

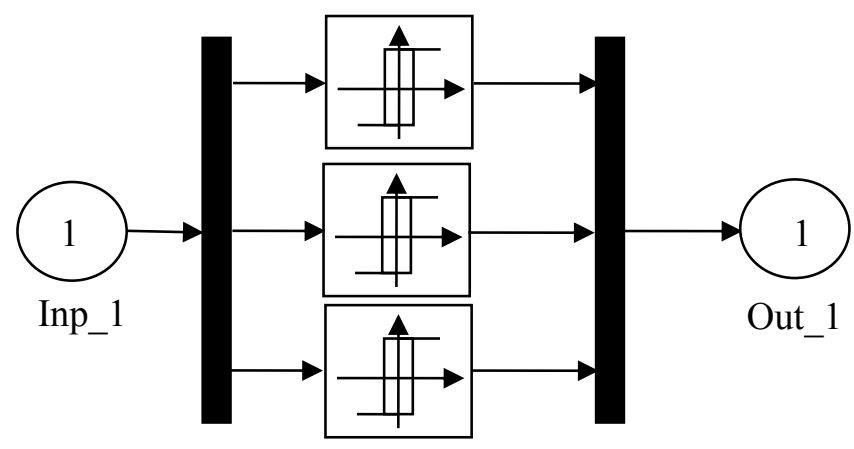

Fig. 5 Block diagram of hysteresis comparators.

\section{Simulation results}

Simulations of the proposed control techniques for a DFIGbased wind turbine are conducted by using the Matlab/Simulink software. The DFIG is rated at $1.5 \mathrm{MW}$ and its parameters are listed in Table 3 [21-22]. The proposed strategies will be tested and compared in two different 
configurations: robustness against parameter variations and reference tracking.

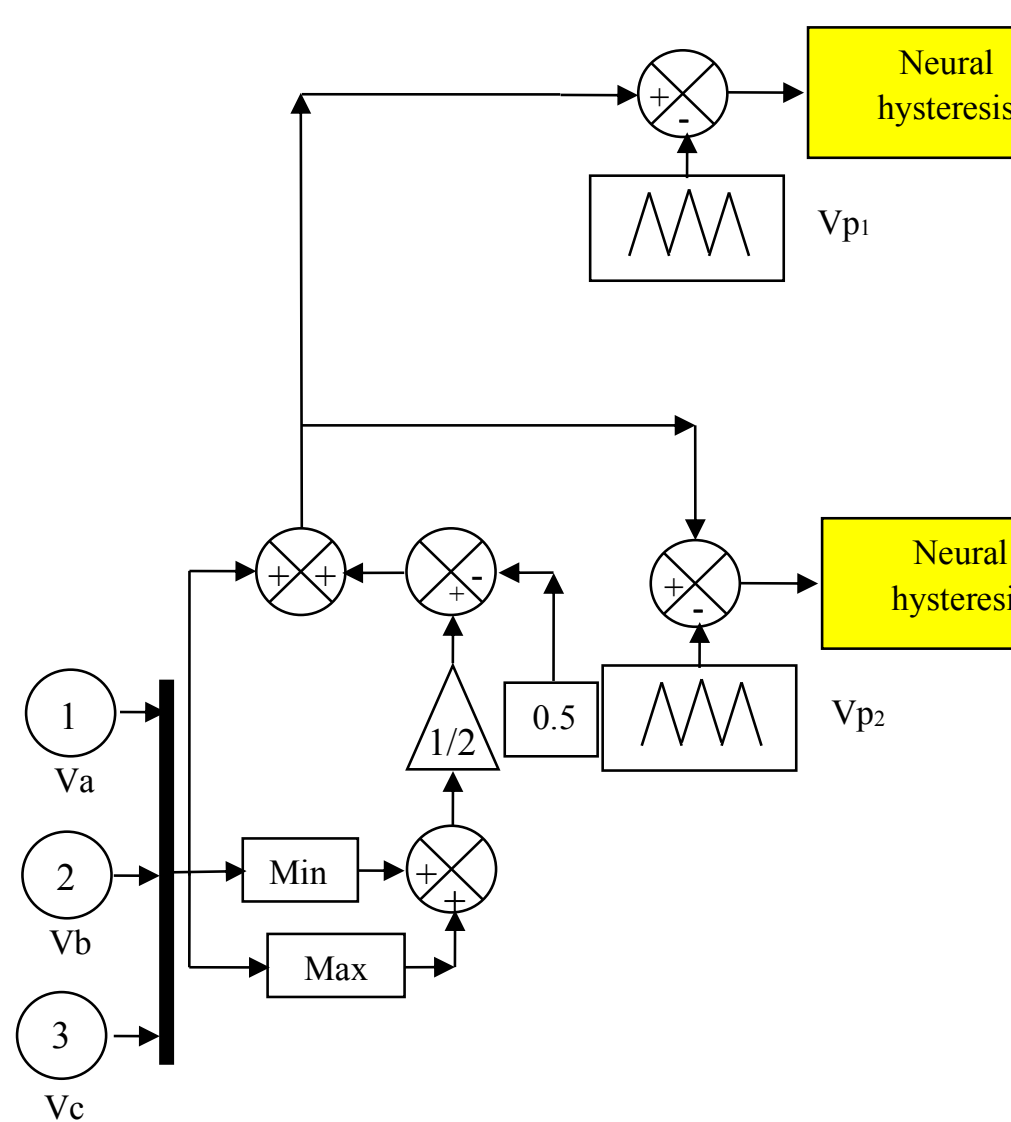

Fig.7 Block diagram of NSVPWM of three-level NPC inverter.

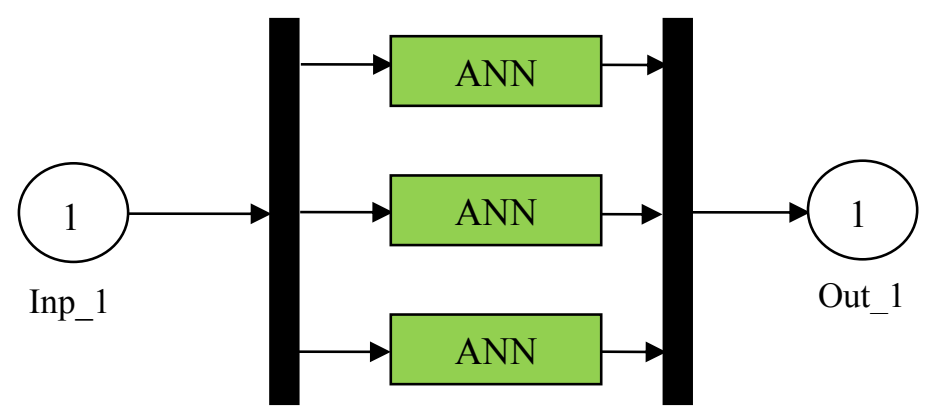

Fig. 8 Block diagram of neural hysteresis comparators.

Table 3. Parameters of the simulated DFIG

\begin{tabular}{cc}
\hline $\mathrm{Pn}$ & $1.5 \mathrm{MW}$ \\
$\mathrm{Vn}$ & $380 \mathrm{~V}$ \\
$\mathrm{p}$ & 2 \\
$\mathrm{Rs}$ & $0.012 \Omega$ \\
$\mathrm{Rr}$ & $0.021 \Omega$ \\
$\mathrm{Ls}$ & $0.0137 \mathrm{H}$ \\
$\mathrm{Lr}$ & $0.0136 \mathrm{H}$ \\
$\mathrm{Lm}$ & $0.0135 \mathrm{H}$ \\
$\mathrm{J}$ & $1000 \mathrm{Kg} \cdot \mathrm{m} 2$ \\
$\mathrm{fr}$ & $0.0024 \mathrm{Nm} . \mathrm{s} / \mathrm{rad}$ \\
$\mathrm{f}$ & $50 \mathrm{~Hz}$ \\
\hline
\end{tabular}




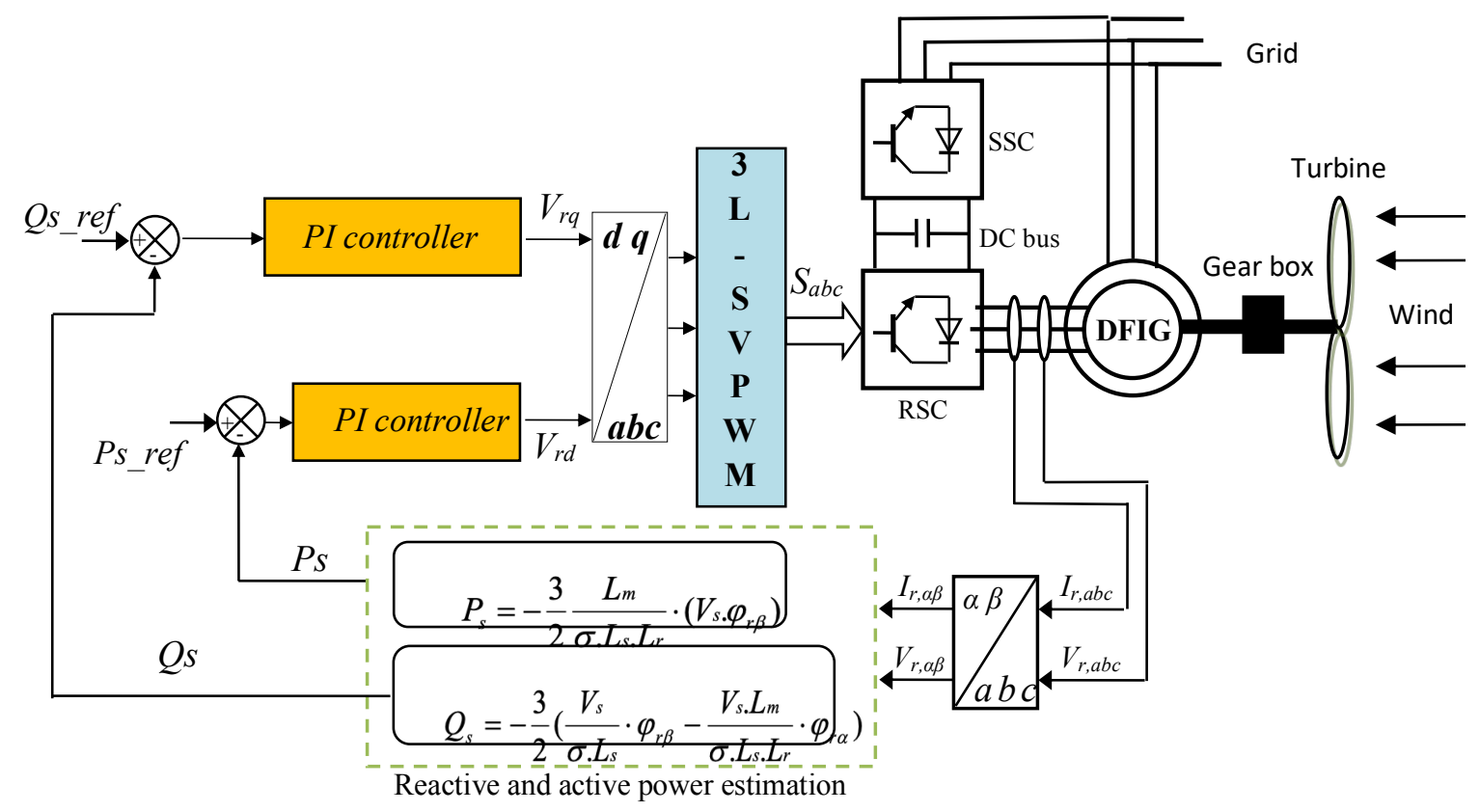

\section{A.Reference tracking test}

Figs 10-14 show the obtained simulation results. For the proposed strategies, the stator reactive and active power tracks almost perfectly their references values. Moreover, the DPC-3L-NSVPWM control scheme reduced the power ripples compared to the classical DPC control (See Figs 1516). The stator current of the DPC-3L-NSVPWM control has low ripples compared to classical DPC (See Fig. 14 and Fig.17). On the other hand, Figs 10-11 shows the harmonic spectrums of one phase stator current of the DFIG-based wind turbine for DPC-3L-NPWM and classical DPC one respectively.

Fig.9 DPC with 3L-NSVPWM technique.

It can be clearly observed that the harmonic distortion is reduced for the DPC-3L-NSVPWM control method (THD = $0.35 \%)$ when compared to classical DPC $(\mathrm{THD}=1.36 \%)$. It is clear from the results that the DPC-3L-NSVPWM has satisfied performance. 

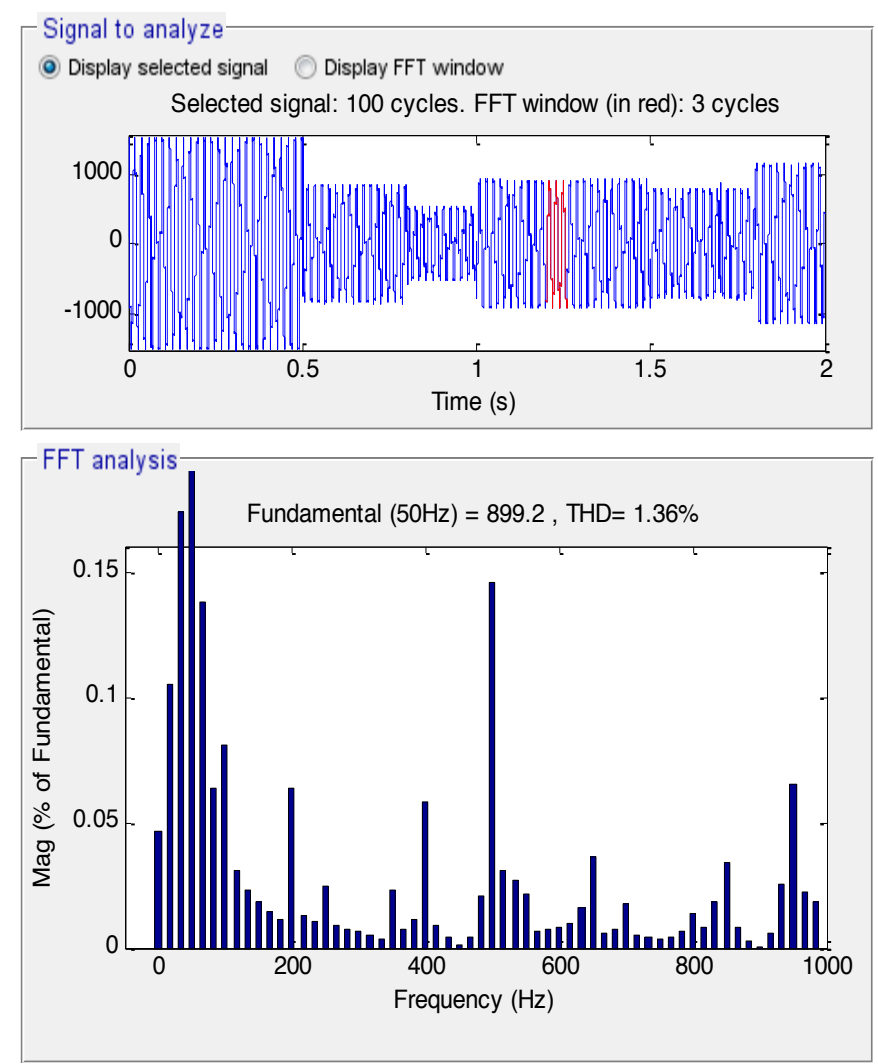

Fig. 10 THD of one phase rotor current for classical DPC (RTT).
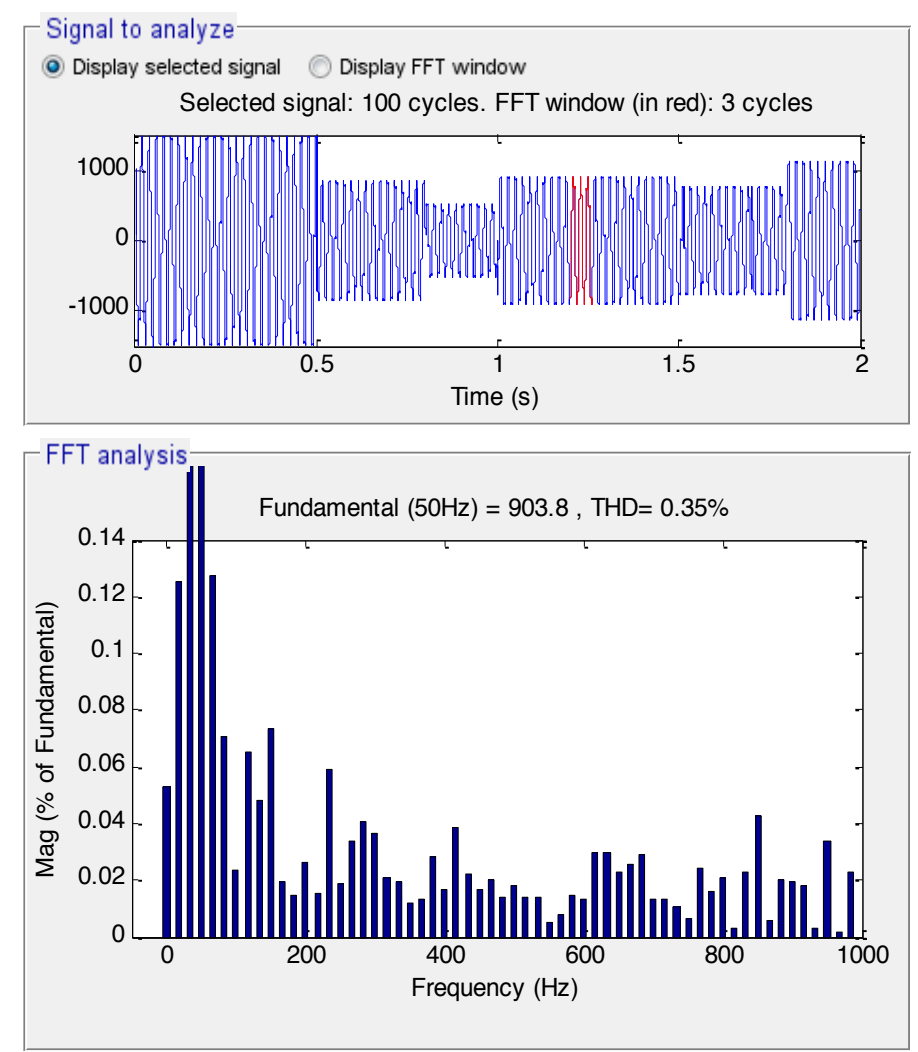

Fig.11 THD of one phase rotor current for DPC-3LNSVPWM (RTT).

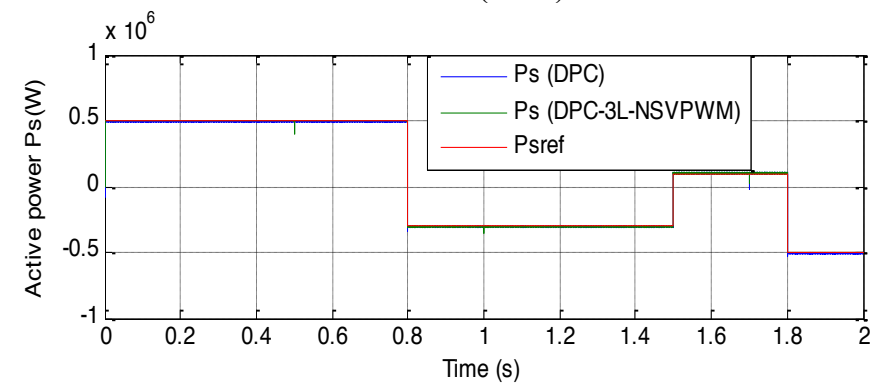

Fig.12 Active power (RTT).

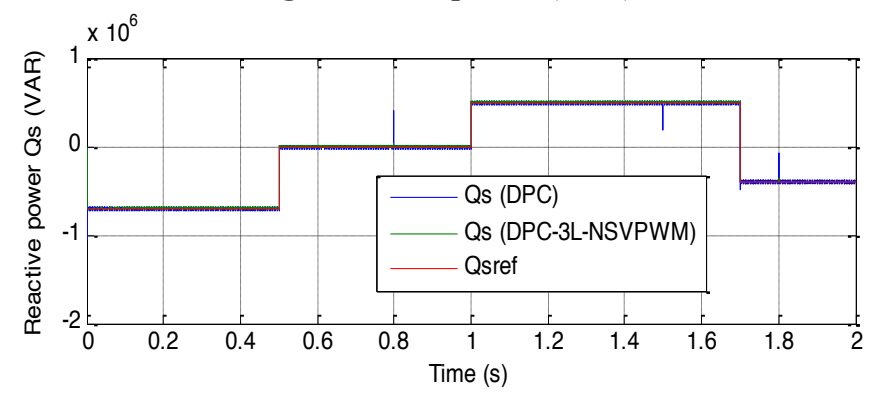

Fig.13 Reactive power (RTT). 


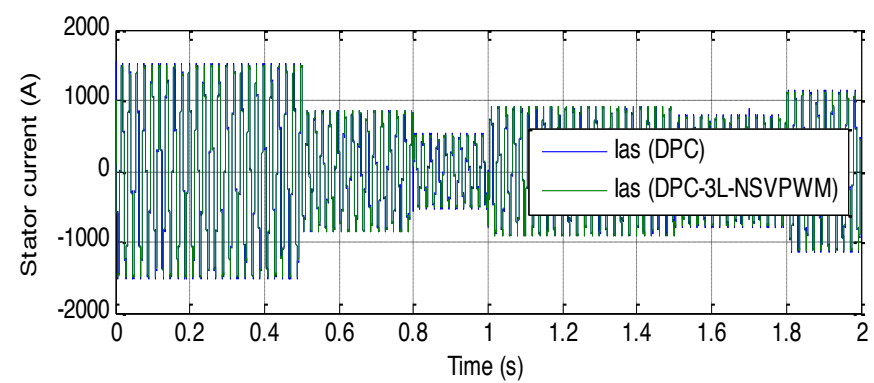

Fig.14 Stator current (RTT).

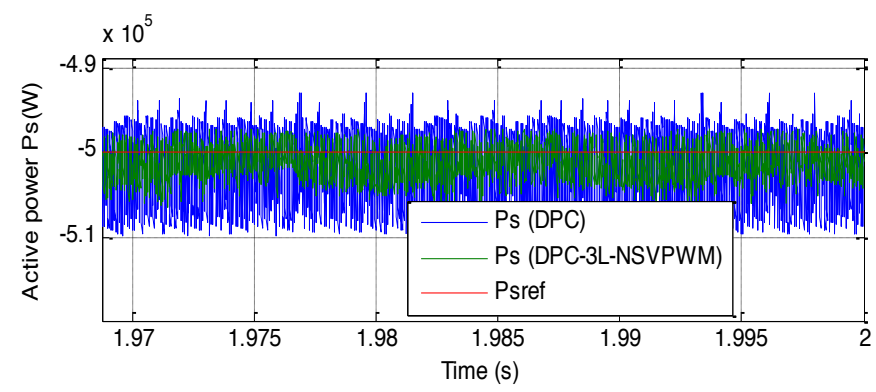

Fig.15 Zoom in the active power (RTT).

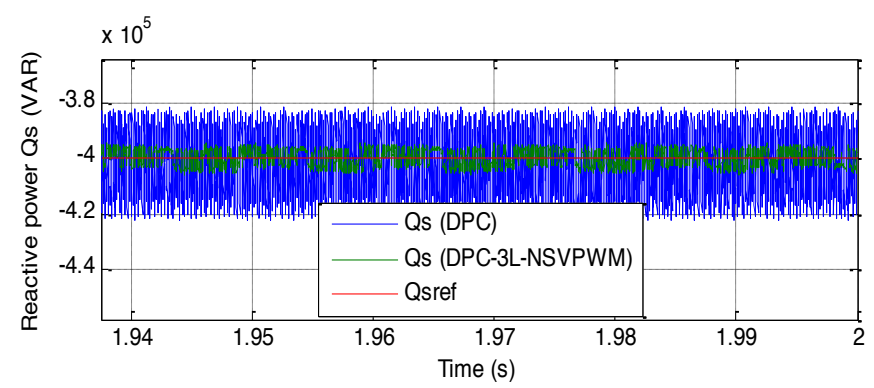

Fig. 16 Zoom in the reactive power (RTT).

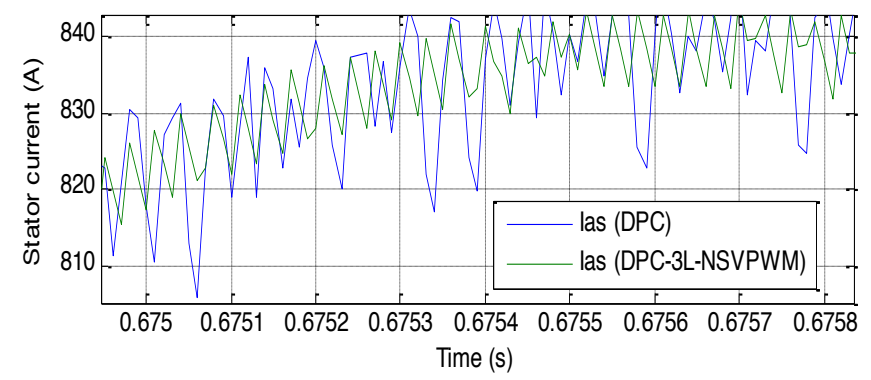

Fig. 17 Zoom in the stator current (RTT).

\section{B.Robustness test}

In this section, the nominal value of the $\mathrm{R}_{\mathrm{r}}$ and $R_{S}$ is multiplied by 2 , the values of inductances $L_{s}, \mathrm{M}$, and $L_{r}$ are multiplied by 0.5 . Simulation results are presented in Figs 18-25. As it's shown by Figs 18-19, the harmonic distortion is reduced for the DPC-3L-NSVPWM control method (THD $=0.77 \%$ ) when compared to classical DPC $($ THD $=2.75 \%)$. On the other hand, the active and reactive powers track almost perfectly their reference values and the effect appears more important for the DPC compared to the DPC-
NSVPWM control scheme (See Figs 23-24). The stator current of the DPC-3L-NSVPWM control has low ripples compared to classical DPC (See Fig. 22 and Fig.25). Thus it can be concluded that the DPC-NSVPWM control scheme is more robust than the classical DPC control scheme.
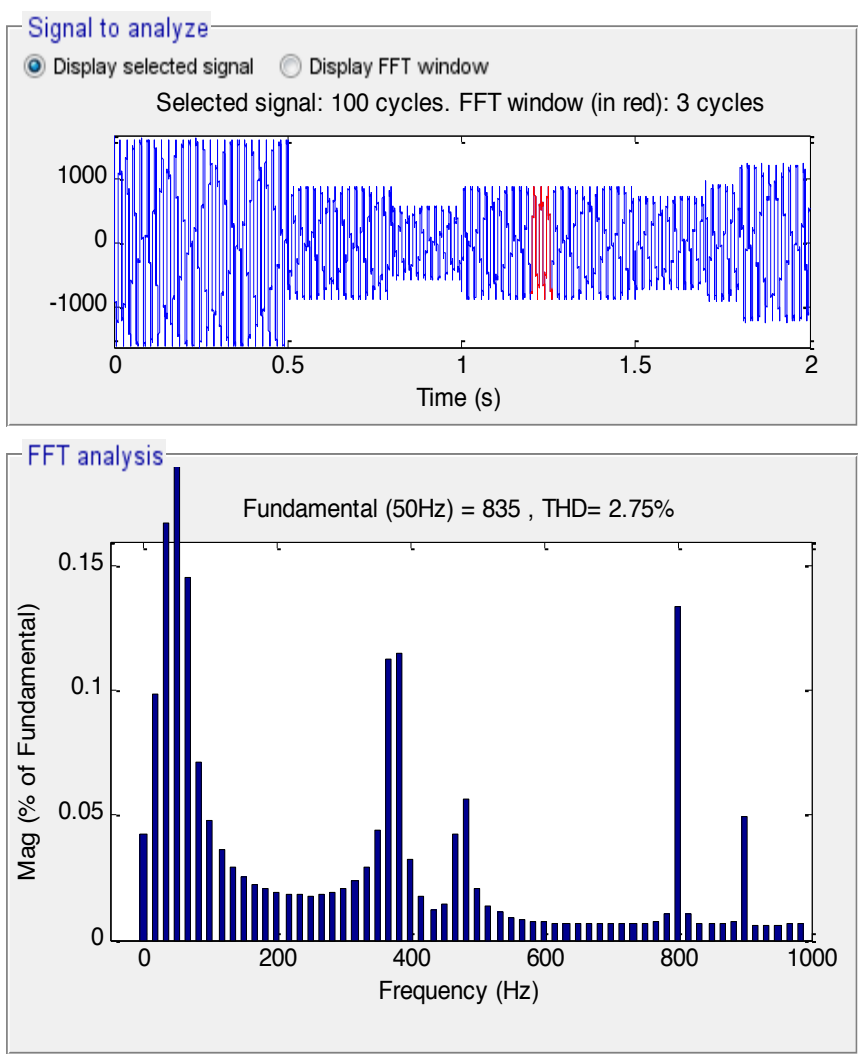

Fig. 18 THD of one phase rotor current for classical DPC (RT). 

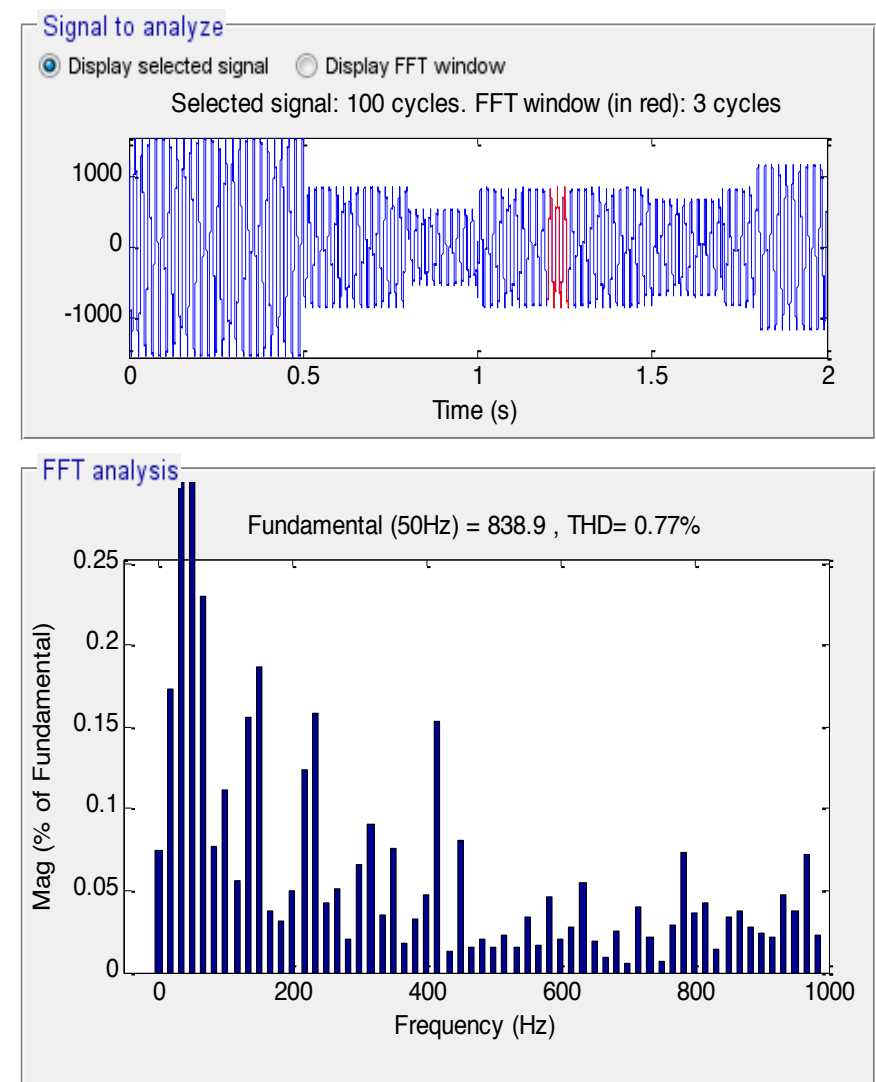

Fig. 19 THD of one phase rotor current for DPC-3LNSVPWM (RT).

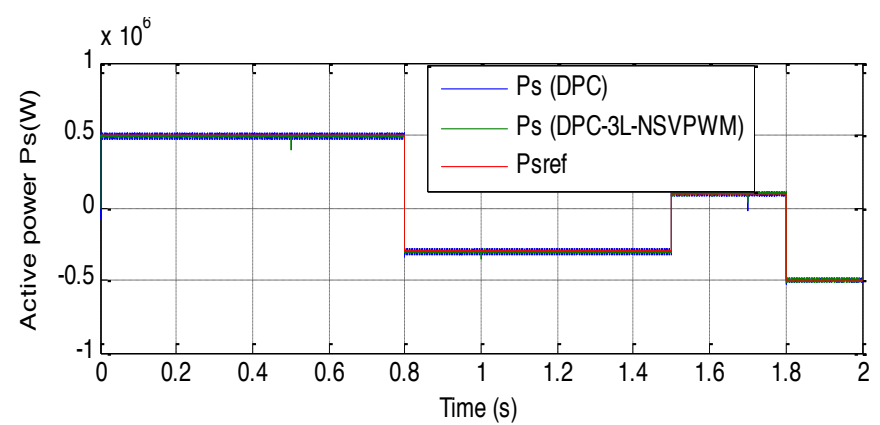

Fig. 20 Active power (RT).

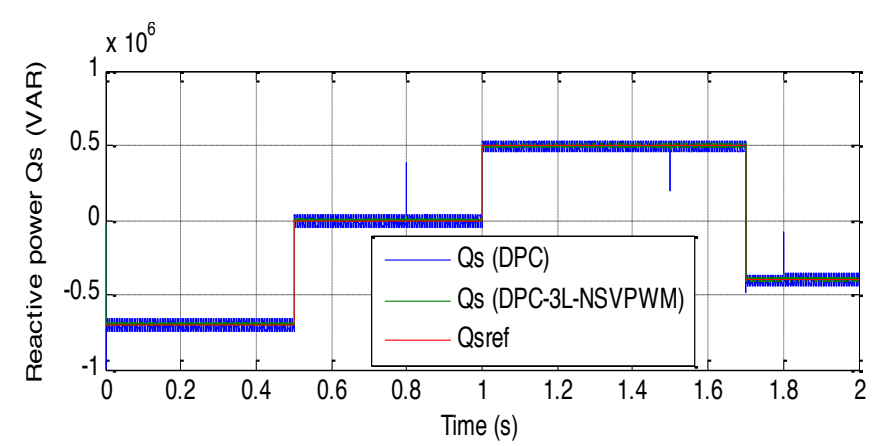

Fig. 21 Reactive power (RT).

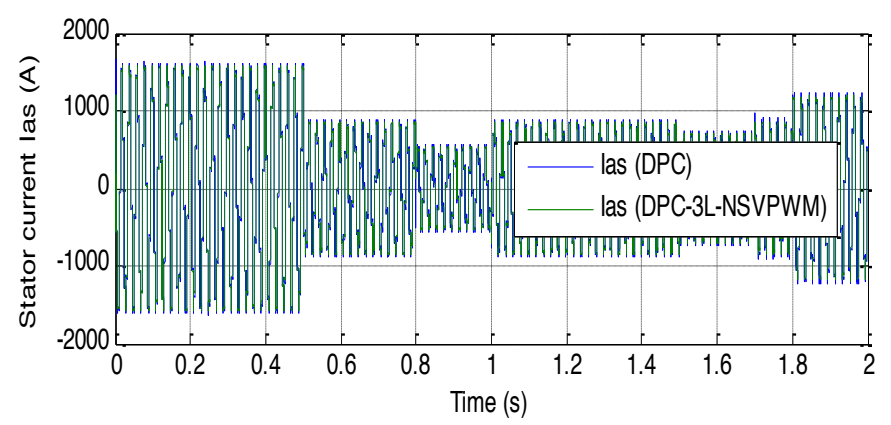

Fig. 22 Stator current (RT).

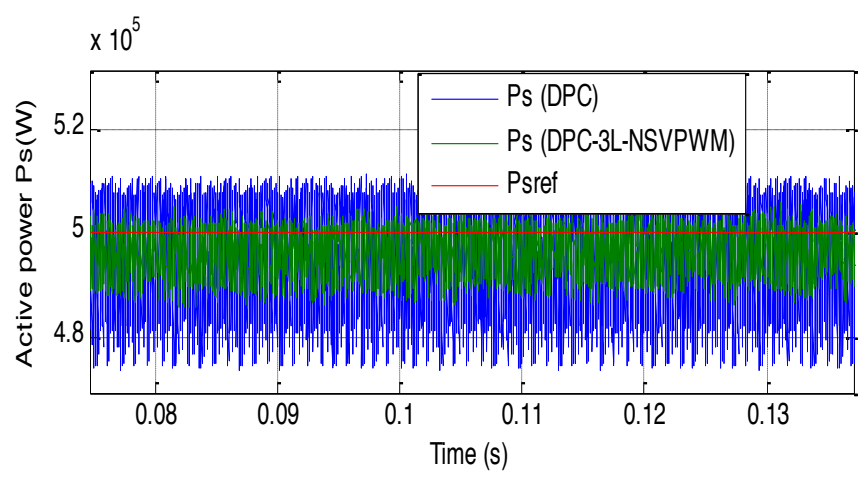

Fig. 23 Zoom in the active power (RT).

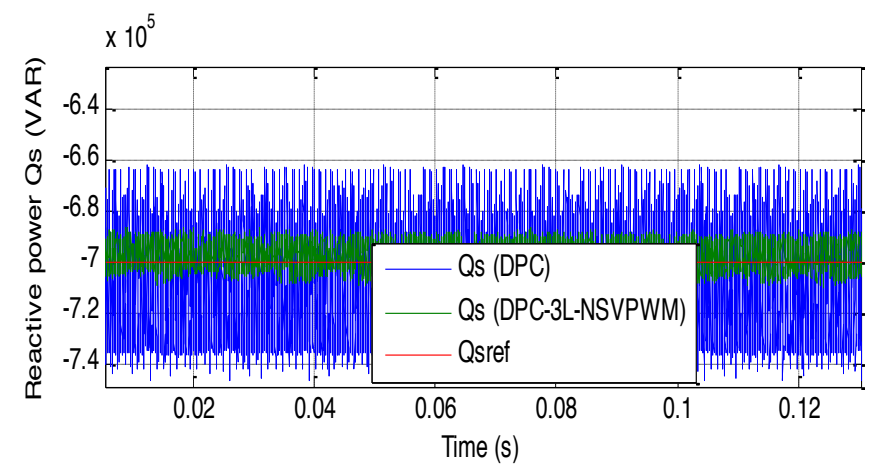

Fig. 24 Zoom in the reactive power (RT).

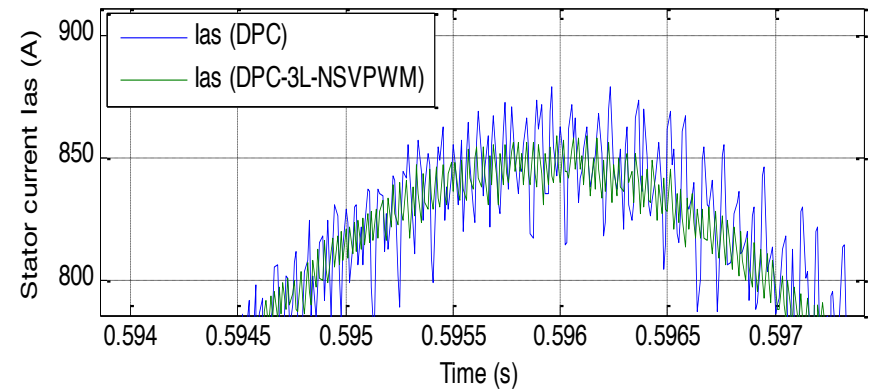

Fig. 25 Zoom in the stator current (RT).

\section{Conclusion}

This work presents the application of a three-level NSVPWM technique for active and reactive powers control of a DFIG controlled by the DPC control scheme. With results obtained from simulation, it is clear that for the same operation condition, the DPC-3L-NSVPWM control scheme 
reduces the active power ripple, harmonic distortion of stator current and reactive power ripple compared to classical DPC control scheme.

\section{References}

[1] E. G. Shehata, « Sliding mode direct power control of RSC for DFIGs driven by variable speed wind turbines, » Alexandria Engineering, 2015.

[2] H. Benbouhenni, Z. Boudjema, A. Belaidi, « Indirect vector control of a DFIG supplied by a twolevel FSVM inverter for wind turbine system, " Majlesi Journal of Electrical Engineering, Vol. 13, No. 1, pp. 45-54, 2019.

[3] Z. Boudjema, R. Taleb, Y. Djerriri, A. Yahdou, «A novel direct torque control using second order continuous sliding mode of a doubly fed induction generator for a wind energy conversion system, " Turkish Journal of Electrical Engineering \& Computer Sciences, Vol. 25, pp. 965-975, 2017.

[4] H. Benbouhenni, «Direct power control of a DFIG fed by a seven-level inverter using SVM strategy, » International Journal of Smart Grid, Vol. 3, No. 2, pp. 54-62, 2019.

[5] F. Amrane, A. Chaiba, «A novel direct power control for grid-connected doubly fed induction generator based on hybrid artificial intelligent control with space vector modulation, » Rev. Roum. Sci. Techn.-Electrotechn. Et Energ, Vol. 61, No. 3, pp. 263-268, 2016.

[6] A. Izanlo, S. A. Gholamian, M. V. Kazemi, «Comparative study between two sensorless methods for direct power control of doubly fed induction generator, " Rev. Roum. Sci. Techn.Electrotechn. Et Energ, Vol. 62, No. 4, pp. 358-364, 2017.

[7] Z. Boudjema, R. Taleb, A. Yahdou, « A new DTC scheme using second order sliding mode and fuzzy logic of a DFIG for wind turbine system, » International Journal of Advanced Computer Science and Application, Vol. 7, No. 8, pp. 49-56, 2016.

[8] H. Benbouhenni, Z. Boudjema, A. Belaidi, « Using three-level Fuzzy space vector modulation method to improve indirect vector control strategy of a DFIG based wind energy conversion systems, " International Journal of Smart Grid, Vol. 2, No. 3, pp.155-171, 2018.

[9] H. Benbouhenni, «Application of five-level NPC inverter in DPC-ANN of doubly fed induction generator for wind power generation systems, " International Journal of Smart Grid, Vol. 3, No. 3, 2019.
[10] S. Z. Chen, N. C. Cheung , K. C. Wong, J. Wu, «Integral Sliding-mode direct torque control of doubly-fed induction generators under unbalanced grid voltage, » IEEE Transaction on Energy Conversion, Vol. 25, No. 2, pp. 356-368, 2010.

[11] M. S. Raj, T. Saravanan, V. Srinivasan, «A modified direct torque control of induction motor using space vector modulation technique, » MiddleEast Journal of Scientific Research, Vol. 20, No. 11, pp.1572-1574, 2014.

[12]J. Hu, J. Zhu, D. G. Dorrell, « Predictive direct power control of doubly fed induction generators under unbalanced grid voltage conditions for power quality improvement, » IEEE Transactions on Sustainable Energy, Vol. 6, No. 3, 2015.

[13] Wa Y., Yang W., « Different control strategies on the rotor side converter in DFIG-based wind turbines, » Energy Procedia, Elsevier, Vol. 100, pp. 551-555, 2016.

[14] M. V. Kazemi, A. S. Yazdankhah, H. M. Kojabadi, « Direct power control of DFIG based on discrete space vector modulation, » Renewable Energy, Vol. 35, pp. 1033-1042, 2010.

[15] Bekakra Y., Ben Attous D., « Comparison study between SVM and PWM inverter in sliding mode control of active and reactive power control of a DFIG for variable speed wind energy, » International Journal of Renewable Energy Research, Vol. 2, No. 3, pp. 471-476, 2012.

[16] H. Benbouhenni, Z. Boudjema, A. Belaidi, «Sliding mode with neural network regulator for DFIG using two-level NPWM strategy, » Iranian Journal of Electrical and Electronic Engineering, Vol. 15, No. 3, pp. 411-419, 2019.

[17] H. Benbouhenni, Z. Boudjema, A. Belaidi, " DFIG-based WT system using FPWM inverter, " International Journal of Smart Grid, Vol. 2, No. 3, pp.142-154, 2018.

[18]H. Benbouhenni, Z. Boudjema, A. Belaidi, «Using four-level NSVM technique to improve DVC control of a DFIG based wind turbine systems, » Periodica Polytechnica Electrical Engineering and Computer Science, Vol. 63, No. 3, pp. 144-150, 2019.

[19] H. Benbouhenni, «Comparative study between direct vector control and fuzzy sliding mode controller in three-level space vector modulation inverter of reactive and active power command of DFIG-based wind turbine systems, " International Journal of Smart Grid, Vol. 2, No. 4, pp. 188-196, 2018.

[20]H. Benbouhenni, «Hybrid neural sliding mode control of a DFIG speed in wind turbine, » Majlesi 
Habib Benbouhenni, Vol.3, No.4, December 2019

Journal of Energy Management, Vol. 6, No. 4, pp. 31-41, 2017.

[21] H. Benbouhenni, Z. Boudjema, A. Belaidi, «A novel matlab/simulink model of DFIG drive using NSMC method with NSVM strategy, » International Journal of Applied Power Engineering (IJAPE), Vol. 8, No. 3, pp. 221-233, 2019.

[22] H. Benbouhenni, Z. Boudjema, A. Belaidi, «Direct vector control of a DFIG supplied by an intelligent SVM inverter for wind turbine system, " Iranian Journal Of Electrical \& Electronic Engineering, Vol. 15, No. 1, pp. 45-55, 2019. 